\title{
Basic Terms of Medical Law and Health Law
}

\author{
Sinisa Franjic \\ Department of Family Medicine at Faculty of Medicine Osijek of Josip Juraj Strossmayer University of Osijek, Osijek, Republic of Croatia
}

Email address:

sinisa.franjic@gmail.com

\section{To cite this article:}

Sinisa Franjic. Basic Terms of Medical Law and Health Law. International Journal of Biomedical Science and Engineering. Special Issue: Medical Law, Health Law and Bioethics as An Imperative for a Better Tomorrow. Vol. 3, No. 3-1, 2015, pp. 6-9.

doi: $10.11648 /$ j.ijbse.s.2015030301.12

\begin{abstract}
Basic terms of health law of those concepts that are encountered in the performance of any of the health services. There are a lot, and these are only those considered most important. It should be noted that in theory, many put an equal sign between the concepts of medical law and health law. These terms should not be placed equal sign because the medical law only applies to relations that occur between specialists that patients provide only some of the medical services, and health law is a much broader concept. Although their legal nature different, they share the most basic terms.
\end{abstract}

Keywords: Medical Law, Health Law, Health

\section{Definitions}

\subsection{Introduction}

While there are technical literature, which mostly dates back to the eighties and nineties of XX. century, medical law and health law its stronger affirmation of beginning to implement the beginning of XXI. century because just then beginning to frequently observe all medical activities through the prism of rights. The public have appeared in cases which is the right to arbitrate in their own way, especially the part of legal science who called criminal law. To lawyers could successfully deal with everything what makes this relatively new scientific discipline, they should know basic sources of medical and health rights. Basic sources are important because in a very simple way of explaining what the medical and health right deal. Basic sources of medical and health law there are the basic concepts which is dedicated to this work. For medical and health law can be said to be in most of the world still developing as a separate legal discipline, while, for example, the United States, well developed. This can be proved through valuable texts group of American doctors who discuss different issues from their field of work [1].

\subsection{Medicine}

Medicine is the science of treating diseases.

Although in medicine and health as an important scientific discipline there are many definitions of medicine, we believe that this is best suited for the simple reason because the patient goes to the doctor when sick with the hope that it will help him, and healed him. So, on the one hand we have a patient in need of medical help, on the other hand we have a doctor who will provide him with the necessary assistance.

\subsection{Health}

Health is a state of complete physical, mental and social well-being, and not just freedom from disease or disability.

This definition of the World Health Organization means that the quality of health care must not only individuals but also society as a whole. The lack of physical or mental deficiencies and life in social welfare with the feeling that the company is participating as a member of his useful presents a description of a healthy man. For health workers, this means that there are no symptoms of the disease, and for society, this means you must ensure social well-being, and quality of life for its members.

\subsection{Health}

Health is a social activity in which health workers to specific assets, equipment and methods of working to improve population health, preventing disease and to detect, diagnosis, treatment and rehabilitation.

The health care system is part of a larger system within which it operates [2]. On the other hand, the scheme consists of a number of subsystems that together make up a whole and ensure that the system achieves its objectives and purpose of existence. Configure health system inevitably influenced by his fundamental goals and values. 


\subsection{Health Care}

Health care is a system of social, group and individual measures, services and activities to maintain and improve health, disease prevention, early diagnosis, timely treatment and medical care and rehabilitation.

Health Protection Act by any state in the world, mainly says that every person has a right to health care and the ability to achieve the highest possible level of health in accordance with the provisions of this Law and the Law on Compulsory Health Insurance. It should be pointed out that each person is obliged to take care of their health and that no one may endanger human health. Also, we should point out that each person in emergencies required to provide first aid to the injured or sick person and allow her access to urgent medical assistance.

\subsection{Health Insurance}

Health insurance are established standards and norms of health care.

Health insurance, for example, in Croatia are subject to mandatory health insurance as a voluntary health insurance. Law on Compulsory Health Insurance regulates the mandatory health insurance in the Republic of Croatia, the scope of the right to health care and other rights and obligations of the compulsory insured persons, conditions and manner of acquiring and financing, as well as the rights and obligations of the compulsory health insurance, including the rights and obligations contracting entities responsible for implementing the health care from the compulsory health insurance. According to the Law on Voluntary Health Insurance, health insurance is: supplementary health insurance, additional and private health insurance.

\subsection{The Health Worker}

The health worker is a person who has a medical education and direct as his profession provides health care to individuals with obligatory adherence to moral and ethical principles of health profession.

Health Protection Act [9] says that the health worker to educate the medical, dental, pharmacy and biochemistry faculty and other university health and also at secondary medical schools. The obligation of health workers to the provision of health care act according to the rules of medical profession, so that their actions do not endanger human life and health. The health worker can be provided against liability for damage that they may cause to the performance of health care operations.

\subsection{Law}

It's a set of legal rules and social norms that govern relations between people and organizations.

Legal rules are the laws and regulations adopted based on them, and social norms are rules of conduct that regulates and penalizes states. Thus, the meaning of this definition is that there are no laws or legal regulations must be observed, and one who does not respect them, will be sanctioned.

\subsection{Medical Law}

Medical law is a set of legal rules governing the relations between the provider of medical services - patient.

Like any separate legal discipline, and medical law has its sources (Constitution, Law, By-laws, etc.) governing the provision of medical services. First on the list of medical service are, of course, doctors, and then followed by dentists, medical biochemists, nurses, pharmacists and physiotherapists. There is specific legislation that says it is of the following experts in their areas must treat the patient. So, as it says and prof. Zvonimir Šeparović [3], medical law is more comprehensive because it covers the whole field of medicine such activities. This thesis is somehow accepted Tatjana Babić and Sunčica Roksandić [4] when they say that medical law defines the relationship between doctor and patient as providers and users of health care and only secondarily includes other health care professionals in their area of regulation.

\subsection{Health Law}

Health law is a set of legal rules governing the relations between the provider of medical services - the patient provider of special medical services.

From this definition it can be seen that the medical and health law are inextricably linked. To make certain the patient was well cared for, and sometimes must ask and service provider of special medical services. Article 3 of the Law on Health Care [9] describes it thusly: "Every person has a right to health care and to possibility achieve the highest possible level of health, in accordance with the provisions of this Act and the Health Insurance Act". For a concrete example, it looks like this: a patient whose weakened eyesight goes to see a doctor, a specialist ophthalmologist, who determines what is his vision (i. e., whether it is negative or positive values) and patient prescribed diopter A patient with this finding goes to the optician who makes his prescribed glasses, and the cost of litigation covered by the Croatian Institute for Health Insurance.

\subsection{Providers of Medical Services}

Provider of medical services is a qualified person for the provision of medical services [5].

Providers of medical services can be a doctor, dentist, medical biochemist, a nurse and pharmacist. These experts must have a university degree or completed the appropriate faculty. Master profession, for now, is not required only of nurses, and medical technicians.

\subsection{The Service of Special Medical Services}

Provider of special medical services is a qualified person for the provision of specific medical services [5].

Provider of special medical services can be a master for making dentures, master optician, insurer. These 
professionals must complete the appropriate high school.

\subsection{Patient}

The patient is a person who need of medical assistance.

With this definition does not require additional explanation, but it should be repeated that the Health Care Act states that every person has the right to health care and the prospect of achieving the highest possible level of health in accordance with the provisions of the Law and the Law on Compulsory Health Insurance.

\subsection{Sick Person}

Sick person is a person suffering from some disease.

Even with this definition does not require additional explanation, but we must emphasize that the concepts of the patient and the patient can not synonymous although you allow individuals putting the equal sign between them. A single visit to the doctor and long-term treatment in no way be compared and it was therefore defined terms the patient and sick person so as defined. In other words, sometimes it is enough one-time visit to the doctor for a successful outcome of a particular health problem, and sometimes for the same need long-term treatment which depends on the health of the person who requested medical assistance.

\subsection{Medical Informatics}

Medical informatics is the scientific discipline concerned with the theory and practice of information processes in medicine.

Today's modern era of modern information technology is unthinkable without the use of computers in all spheres of life as well as in medicine. Data processing is one of the most important tasks of medical informatics as a fast and efficient resolution of certain issues in different areas of medicine.

\section{Implementation of Health Care}

The systems of health policy at the center of the continuing interest of the public in particular, therefore, it is an area of life and death in the most literal sense of the word. The disease is, as a major life but also social risks, not just a priority area for medical or public health interventions, but also the area of special social welfare state. This concern is most often expressed in complex state-controlled health insurance schemes and national concern about the overall organization of health care [6].

In the life of individuals, families, groups and communities often sudden, unpredictable and unplanned events occur that may endanger life, impair health, distracted people in their planned activities, adversely affect the economic power of the individual, family or community [7].

Health care is a system of social, group and individual measures, services and activities for the conservation and improvement of health, prevention of disease, early diagnosis, timely treatment and medical care and rehabilitation. Such risk events are associated Hovering on the biological function of the body and life of the individual and the family (birth, death, illness), family life (education and upbringing of children, care for the elderly and disabled), professional activity (accidents at work, disability, unemployment), natural disasters (earthquakes, floods) and social crisis (wars, economic stagnation, migration). Part of such risk events, which are associated with health, community solves, reduces or prevents, usually on the principles of solidarity and reciprocity of community members, organized measures, activities and actions that we call health care.

Every person has a right to health care and the prospect of achieving the highest possible level of health, in accordance with the provisions of the Health Protection and the Law on Compulsory Health Insurance. Every person is obliged to take care of their health. No one may endanger the health of others. Every person is in an emergency reserve to provide first aid to the injured or sick person and allow her access to urgent medical assistance.

Health activities and protection are a reflection of social relations, economic conditions and political system of the country on the one hand (social factors) and scientific knowledge and achievements of medical practice on the other hand (technical and professional factors) [8]. The contribution of health to development and progress of the community is monitored not only as a contribution to the general progress and welfare of the community, but it is considered to be a participant in the direct production.

\section{Conclusion}

As a new scientific discipline, medical and health law is more intense in the Republic of Croatia began to develop at the beginning of XXI. century, although there are experts who were engaged in medical and health law and earlier, or those who wrote the eighties and nineties of the twentieth century. Great progress can be considered the adoption of the Law on the protection of the rights of patients who spoke clearly about what rights patients and sick persons. On the other hand, the providers of medical services have laws that prescribe how these segments in fulfilling its tasks should behave. In their work, health care providers must adhere to regulations that study the traditional legal disciplines. This means that the medical and health law, as separate scientific discipline related to almost all disciplines which are taught in law schools, but it also means that it is a very complex legal issues. As can be seen, medical law is very extensive scientific discipline with the tendency of further development. Accordingly, medical law is still developing, and this work represents a small contribution in this regard. Basic definitions of medical and health rights are important precisely because in order to facilitate the further development of medical and health rights as separate disciplines within the law as a whole. Basic definitions of medical rights is through their descriptions provide guidance for the further development of medical and health law. 


\section{Nomenclature}

$\mathrm{NN}=$ Narodne novine $=$ National newspaper

\section{References}

[1] First www.physiciansnews.com

[2] Kovačić, Luka and associates: "The organization and management in health care," Medicinska naklada, Zagreb, 2003.

[3] Šeparović Zvonimir: "The limits of risk" - Ethical and legal approaches to Medicine, Third, revised and updated edition, Informator, Zagreb, 1998.

[4] Babić, Tatjana and Roksandić, Sunčica: "Basics of health law", Tipex, Zagreb, 2006.
[5] Franjić, Siniša: "Basic sources of medical law", JAHR, Year 4, Number 8, Rijeka, December 2013.

[6] Zrinščak, Siniša: "Systems of health policy in the world - the basic features of the current processes", Revija za socijalnu politiku, 1/1999.

[7] Jakšić, Želimir; Kovačić, Luka and associates: "Social Medicine", Medicinska naklada, Zagreb, 2000.

[8] Jaksic, Želimir et al: "Social medicine - Practicum I", sixth revised edition, Faculty of Medicine, University of Zagreb, Zagreb, 1992.

[9] Law on Health Care - NN 150/2008.; 71/2010; 139/2010.; 22/2011.; 84/2011.; 154/2011.; 12/2012 .; 35/2012.; 70/2012.; 82/2013.; 159/2013.; 22/2014.; 154/2014. 